\section{$020-021$ \\ Noticias y comentarios \\ PH42 - Febrero 2003}

Tanto las sesiones científicas como los expositores estuvieron a un muy buen nivel y, sin duda alguna, sirvieron de experiencia para las Jornadas sobre Patrimonio, Turismo y Desarrollo Territorial que se celebrarán en Úbeda durante este mes de febrero. Estas últimas, auspiciadas por la Asociación de Geógrafos Españoles y la Consejería de Cultura de la Junta de Andalucía, se suman a las propuestas para el debate de organismos internacionales (UNESCO, Consejo de Europa...) sobre Patrimonio Cultural y DesarroIlo Territorial. El encuentro se dirige a profesionales, instituciones públicas y actores locales vinculados a la gestión del patrimonio, del turis- mo de interior y del desarrollo territorial, con el fin de promover la cultura territorial en la sociedad y los medios de comunicación.

\section{Raúl Puente Asuero}

Grupo de Investigación

Geografía y Desarrollo Regional y Urbano

Universidad de Sevilla

Más información sobre las Jornadas de Úbeda:

Asociación de Geógrafos Españoles

Tel./Fax: 915643477

secretaria@age-es.org
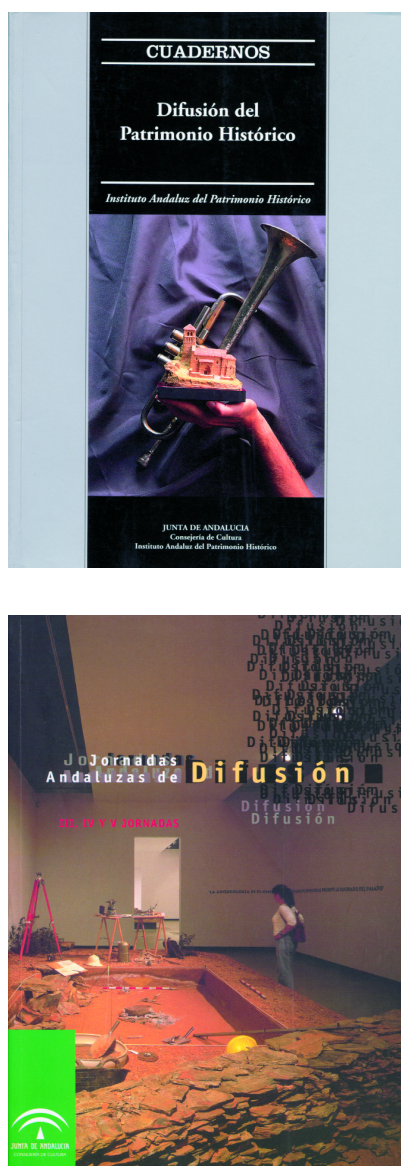

\title{
Evaluar, objetivo prioritario de las próximas Jornadas Andaluzas de Difusión (Almería, 2004)
}

Tras casi 10 años de trabajo en las Jornadas Andaluzas de Difusión, el Servicio de Investigación y Difusión de la Dirección General de Bienes Culturales de la Consejería de Cultura de la Junta de Andalucía planteó el VII encuentro (Huelva, noviembre de 2002) como un lugar de reunión en el que se expusieran diversos modelos de gestión y difusión del patrimonio local, tanto en el ámbito nacional como en el territorio común europeo.

El número de comunicaciones propuestas a los organizadores resultó elevado, por lo que sólo se seleccionaron aquellas centradas en la difusión en el territorio, al tiempo que se desestimaron las que planteaban temas de investigación o proyectos que aún no estaban en marcha. Las 43 contribuciones seleccionadas se agruparon en tres grandes bloques, introducido cada uno por una conferencia:

> La difusión del patrimonio: teoría y planteamientos prácticos

> Gestión pública y agentes sociales en la difusión del patrimonio histórico

\section{> Territorio y patrimonio histórico}

Mikel Corbishley, de English Heritage, presidió la primera sección. Su conferencia trató sobre la difusión del patrimonio al público escolar anglosajón desde una empresa pública. En este bloque se agruparon varias comunicaciones sobre la teoría de la difusión, el papel que desde los organismos internacionales se da a las corporaciones locales en materia de tutela y difusión o cómo se puede utilizar el patrocinio y mecenazgo. Esta sección se cerró con diversas experiencias en la comunicación del patrimonio paleobiológico y arqueológico. En la difusión del patrimonio arqueológico se lleva tiempo trabajando, llevándose a cabo numerosas experiencias, como las realizadas en Almadén de la Plata (Sevilla), Puente Genil (Córdoba) o Vélez Blanco (Almería), que se encaminan a la recuperación integral del patrimonio natural y cultural, la accesibilidad de los yacimientos o su función en el desarrollo sostenible. Sin embargo, el patrimonio paleobiólogico parece el gran olvidado, por lo que parecía interesante dar a conocer estos proyectos, como es el caso del futuro Centro de Interpretación sobre Patrimonio Paleobiólogico que se ejecutará en Lepe (Huelva).

Introdujo el bloque dedicado a la "Gestión pública y agentes sociales en la difusión del patrimonio histórico" Celia Rosell, con una conferencia sobre voluntariado cultural, su papel como agente en la difusión del patrimonio y los cauces que desde la Consejería de Cultura se están utilizando para la colaboración de la administración con el movimiento voluntario. En esta sección se presentaron comunicaciones sobre la función de las asociaciones de vecinos y las de defensa de patrimonio y su papel como asesores - agentes de difusión del patrimonio en el ámbito local. La función del patrimonio como punto de integración y la participación de los ciudadanos en la toma de decisiones fue un tema demandado por los comunicantes. Se trataron interesantes planes, como el que se está realizando en Granada mediante al Plan Urban, que se ha destinado a revitalizar el centro histórico de esta ciudad y su área metropolitana mediante un Programa Común Municipal; o el plan integral de recuperación, puesta en valor y difusión que se está llevando a cabo en algunos municipios como es el caso de Loja. Este último propugna que estos planes de difusión no se ejecuten pensando sólo en el visitante, sino en los habitantes del lugar, de manera que, cono- 
ciendo y valorando su patrimonio lleguen a tutelarlo. En esta línea se presentó una experiencia que se está llevando a cabo en el País Vasco y que supone la recuperación de una zona minero-industrial en la que se hace partícipe a toda la comunidad, un caso similar al que se está llevando en Riotinto (Huelva). Finalmente, se trató el papel de las escuelas taller en la recuperación y puesta en valor del patrimonio.

El tercer bloque, dedicado a "Territorio y Patrimonio Histórico" estuvo presidido por la conferencia de Pedro Salmerón, que trató sobre el Proyecto Alianza, laboratorio europeo en el que el paisaje se utiliza como herramienta de comprensión, análisis y confluencia de los aspectos que determinan el territorio, entendiéndose el patrimonio como un elemento más de un todo. Se completó esta sección con experiencias concretas que se están llevando a cabo en el territorio. Las rutas, ya virtuales, naturales o gastronómicas, se estudiaron como una manera de integrar el patrimonio en el territorio, de no desgajarlo de su entorno, presentándose proyectos como el del Museo de la Villa de Almonte (Huelva), que toma el paisaje como eje estructurador; otra experiencia interesante son las rutas realizadas en Córdoba mediante el Plan UrbanRibera. También se expuso en este bloque la experiencia obtenida por la Consejería de Cultura con su proyecto de Centros de Interpretación del Patrimonio que se han construido (La Frontera Abierta: Al-Andalus y la Sierra, en Almonaster la Real, Huelva) o el que se está llevando a cabo en Zalamea la Real (Huelva) sobre la cultura dolménica, relacionado con el Conjunto Dolménico de El Pozuelo. Esta sección tuvo como eje una mesa redonda, en la que bajo el título La difusión del patrimonio: de la perspec- tiva local al enfoque global, se debatió el papel de las administraciones y de los agentes sociales en la comunicación, los métodos que se utilizan, la incidencia de la globalización y de la sociedad de la información sobre nuestro patrimonio.

El Servicio de Investigación y Difusión ha detectado en esta última edición de las Jornadas -y previamente en las $\mathrm{VI}$ - que la mayoría de las comunicaciones presentadas se centran en proyectos o experiencias en fase de inicio, sin posibilidades, por tanto, de evaluación. Resulta primordial conocer cómo se difunde el patrimonio histórico, pero más importante todavía conocer cuál es su resultado; cómo responde el público; si se cumplen los objetivos que movieron esa iniciativa; si es la mejor manera para comunicar el patrimonio o nos quedamos simplemente en lo anecdótico. Igualmente, hay que plantearse si los métodos que se utilizan son los adecuados o si, por el contrario, predomina el continente sobre el contenido, es decir, los medios que se utilizan sobre lo que se quiere difundir. Por lo tanto, para las VIII Jornadas se plantea fundamentalmente la exposición de proyectos ya ejecutados y evaluados. Para esta nueva convocatoria, que se celebrará en la primavera de 2004, se propone la ciudad de Almería como sede y el tema El Patrimonio Inmueble y su planificación cultural (gestión, interpretación, musealización, puesta en valor y acceso del público a los Bienes Culturales).

\section{Luz Pérez Iriarte}

Servicio de Investigación y Difusión

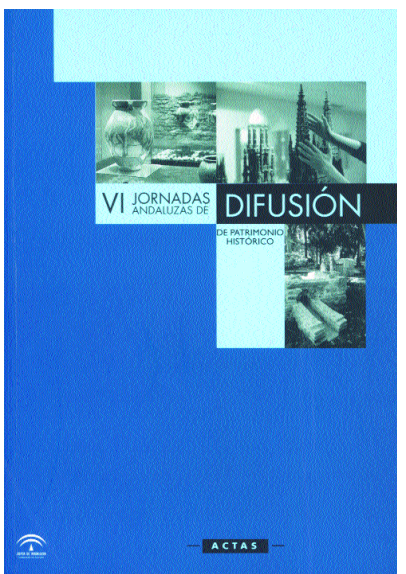

Jornadas Andaluzas de Difusión

\section{Organiza:}

Servicio de Investigación y Difusión de la Dirección General de Bienes Culturales de la Consejería de Cultura de la Junta de Andalucía

\section{Temas:}

> Las I (Sevilla, 1993) y II Jornadas (Sevilla,1994) se dedicaron a la difusión en general y su incidencia en la educación.

> La Arqueología Urbana en la Comunidad Andaluza fue el tema principal de la III edición (Córdoba, 1996).

$>$ Las IV Jornadas (Baeza, 1998) se ocuparon de la interpretación como nueva disciplina que permite el acercamiento del Patrimonio al público.

> La V edición (Cádiz, 2000) versó sobre la didáctica del patrimonio y en especial del arte contemporáneo.
> Las VI Jornadas (Málaga, 2001) consistieron en una convocatoria abierta a todas aquellas personas que pudieran aportar sus experiencias en la comunicación de los bienes culturales.

$>$ Las VII Jornadas (Huelva, 2002) acerca de modelos de gestión y difusión del patrimonio local.

> Las VIII Jornadas (Almería, 2004) analizarán el Patrimonio inmueble y su planificación cultural.

\section{Publicaciones:}

JORNADAS Andaluzas de Difusión (6 ${ }^{\text {a }}$. 2001. Málaga) : actas. Sevilla: Junta de Andalucía, Consejería de Cultura, 2002

JORNADAS Andaluzas de Difusión (III, IV y V Jornadas) [comunicaciones]. Sevilla: Junta de Andalucia, Consejería de Cultura, 2002

DIFUSIÓN del Patrimonio Histórico. Sevilla: Consejería de Cultura, Instituto Andaluz del Patrimonio Histórico, 1996 